\title{
LA-4916-MS
}

AN INFORMAL REPORT

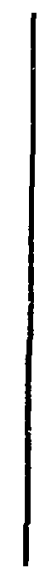

A Microprogrammed Branch Driver (MBD) for a PDP-11 Computer 
This report was prepared as an account of work sponsored by the United States Government. Neither the United Stotes nor the United States Atomic Energy Commission, nor any of their employees, nor any of their contractors, subcontractors, or their employees, makes any warranty, express or implied, or assumes any legal liability or responsibility for the accuracy, completeness or usefulness of any information, apparatus, product or process disclosed, or represents that its use would not infringe privately owned rights.

In the interest of prompt distribution, this LAMS report was not edited by the Technical Information staff.

Printed in the United States of America. Available from National Technical Information Service

U. S. Department of Commerce 5285 Port Royal Road Springfield, Virginia 22151

Price: Printed Copy \$3.00; Microfiche \$0.95 
LA-4916-MS

An Informal Report

UC-32

ISSUED: April 1972

\section{A Microprogrammed Branch Driver (MBD) for a PDP-11 Computer}

by

Lavon R, Bisweil

Robert E. Rajala

î̃ TICE

This roport wh propersd as in sccount of wack eponeored by the United States Government. Netther the United States nor the United Stetes Atomic Bnory Commition, nor any of their employen, nor any of thot contrictors, subcontractore, or thet empleyes, makes any warminty, expreis or implide, or anumes any makes any warmuty, exprew or implidd, or ansuses any plotenas or unofulnas of any informstion, epperatur, product or proces disclosed, or ropresents that its use would not infringe privetoly owned tiphts. 
A MICROPROGRAMMED BRANCH DRIVER (MBD) FOR A PDP-11 COMPUTER

by

Lavon R. Biswell and Robert E. Rajala

ABSTRACT

A microprogrammed branch driver (MBD) is the interface between a Digital Equipment Corporation (DEC) PDP-11 computer and a multicrate CAMAC system. This unit is a multiple, direct memory access (DMA) channel branch driver.

The requirements for an $M B D$ are discussed in the introduction, and stem from a Los Alamos Scientific Laboratory (LASL) study group report on the design of the Los Alamos Meson Physics Facility (LAMPF) dataacquisition system. Because of the desire for a standard system, the types of experiments and data rates, and the varying complexity of dataacquisition systems, it was decided that a microprogrammable, multiple DMA channel branch driver was required.

Basic specifications and capabilities of the MBD are discussed and a block-dlagram-type operation is presented, which includes the modes, registers, priority structure, interrupts, DMA channels, instruction set, branch driver, and inttialization and run procedures. Modes of operation and design options are given, and the standard logic used to fabricate the MBD, the hardware system, is discussed. Included are diagnostic and standard driver routines, and a program example.

\section{INTRODUCTION}

In August 1970 a group met at Log Alamos to develop a system design for the on-line dataacquisition facilities at LAMPF. The results of this study are documented in the report, "LAMPF Data-Acquisition System." 1 A brief summary of this report is given in order to establish the requirements for the microprogrammed branch driver (MBD) discussed in this paper. The work evolved from a cooperative venture between LASL and Bonner Research Laboratories, Rice University, to develop a CAMAC branch driver for the PDP-11 computer. ${ }^{2}$

It was concluded that the system should be developed around a small, dedicated computer. The computer would acquire, preprocess, and record data; monitor the condition of the experimental apparatus; execute necessary control functions; and perform prelininary analyges which forecast the results of the experiment. It was proposed that L4MP provide hardware and sof tware support for the standard system. Recognizing the need to share expensive peripherals and to have access to arithmetic capability of a large computer, it was recommended that a computer-based terminal be installed at LAMPF and linked to the Central Computing Facility (CCF) at the Laboratory. All the dedicated computers would have a link to the terminal, which would give access to 1 ts peripherals, eccelerator data, anc a path to CCF.

It was recomended that in order to accommodate a large number of users with varled interests at LAMPF, all Interfacing between the experimental equipment and the dedicated ccmputers be implemented in the CAMAC standard. The results of the study led to a selection of the DEC PDP-11 as the stariard for the LAMPF data-acquisition system and terminal computer. 
The CAMAC system of instrumeatation 3,4 has been adopted by numerous laboratories in Europe and the United States as a standard method of inter-facing research apparatus, with a goal of establing a stable boundary between instrumentation and computing. A brief description of CAMAC will help clarify the objectives of the wit described in this report. CAMAC replaces the great variety of I/0 buses found on computers with a single, nonproprietary design standardized both mechanically and electrically. The system features a crate which will accept up to 24 modules, and a branch which will accept up to seven crates. The crate dataway and the branch highway provide the communication link to the computer. The CAMAC specification restricts the instrumentation contained in a module only to the extent necessary to insure compatabllity with the crate and dataway.

The dataway has a 24-bit read bus, a 24-bit write bus, ani a control bus. The control bus provides for 16 subaddresses and for performing up to 32 different operations on a module (function codes). Provision is made for polling the station via a common " $Q$ " response line and for verifying valid commands by a common " $X$ " response line. In add1tion to the buses, each individual module has a pair of private lines for module station selection (N-line) and one for its service requests, LAM (Look-at-me).

The above characteristics are not enbodied in the I/O bus of any computer and thus CAMAC must itself be interfaced to the computer. The interface must resolve the line and logical differences between the two structures and 1t.s design will therefore have a significant Influence on the performance of the total system.

To review requirements, the unit wust interface the PDP-1I computer to the CAMAC branch highway. It is also desirable to free the PDP-11 computer for as much real-time data analysis as poss1ble. Many of the experiments have high event rates and with the coming of age of multiwire proportional counters, many of the experiments may have very high data rates. The minimum system requirements are two DHA channels for experimental data (scalers, wire chambers, pulse-helght analyzers, etc.)-one Dis channel to display accumulated data on a storage scope and one DHA channel for cormunication with the LAMPF terminal via the CAMAC data link.

From the requirements it was decided that what was needed was a multiple DMA channel branch driver that could be easily modified or programmed. With the advent of microprogrammable processors, this would give the flexibility required and exploit the maximum capabilities of the PDP-11 computer and the CAMAC system. Therefore, this is the approach taken In the design of the MBD discussed in this report.

GENERAL SPECIFICATIONS AND OPERATION OF MBD

Figure 1 shows a functional diagram of the MBD. The unic can be divided into three major areas: the PDP-11 computer interface, the CAMAC branch driver, and the microprogramed processor.

The branch driver is a very conventional design. It contains three basic registers: the cotnmand register (CNAF), the 24-b1t branch data register (BDR), and the 24-bit graded-I register (GLR). In order to get around the problem of the conmand requiring 17 bits, three different command types are defined: read, write, and control/test. Bit F8 is omitted from the command word and is supplied by the processor, depending on the type of comrand in which it appears. The processor is in complete control of the branch driver. It controls reading and loading the registers, starting the branch operation, and testing the " $Q$ " and " $X$ " 1ines. A branch t1me-out error will generate an interrupt 1dentif1able in the CSR register. The computer INIT init1alize command generates a "BZ" command to the branch. A branch demand (BD) will result in a graded-L (GL) operation if the processor is in the stop mode, but if in the run mode, the processor will not allow a GL operation until it conpletes the current job and generates an extt command. The results of a GL operation are that the GL's from the branch are stored in the GLR. Bits 17-24 of the GLR result in DMA channel requests $0-7$. B1t 24 corresponds to channel 7 and is highest priority. B1ts 16-1 of TLR are masked by the MASK register in computer interface and appear ag 16 unique interrupt vectors to the PDP-11 computer. Btt 16 is the highest priority $L$ request. The IASK register can be loaded only from the PDP-11. Since the BDR is 24 bits in length and the processor and PDP-11 are 16b1t machines, two transfers are required to read 


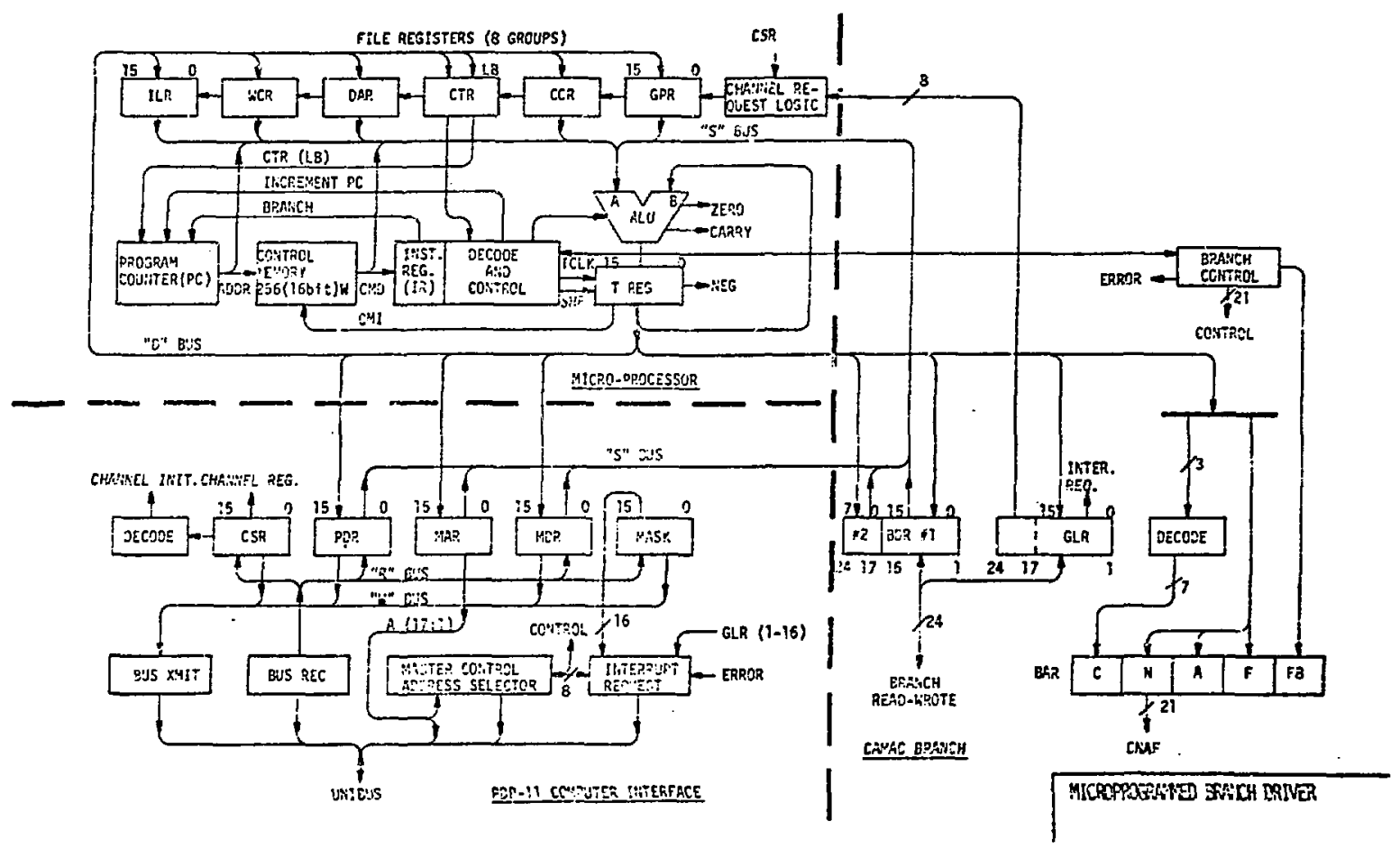

Fig. 1

or load the BDR. Bits 24-17 are the low byte of the second transfer.

The computer interface part of the MBD is very similar to the standard DEC interface. ${ }^{5,6}$ The five registers of the interface are detalled in Table $I$. The memory address register (MAR) and the memory data reglster (MDR) are the DMA channel registers and are controlled from the processor. The processor is bus master during all DMA transfers. A bus request is made when the processor executes a datachannel read or write. The bus is released at the end of each transfer unless the unit has been commanded into the 2-cy -1e mode for increment and addto-memory function; then it is released at completion of the second transfer. A UNIBUS transfer time-out error aets an error interrupt to the computer and an error flag in the CSR register.

The other registers of the interface are the control and status register (CSR), the program data register (PDR), and the MASK register. These registers may be given any device addresses allowed by DEC and are used to initialize the processor; that is, load the control memory of the processor from the computer and read it to verify correct loading. They are also used in the single-cycle (manual) mode for controlling and testing the processor. The CSR register is uged by the PDP-1I to make a channel request when the processor in the run mode by ficting the desired channel number into the channel-select field and run-mode bit set. The balance of the CSR 111 be discussed in depth in the manua1-mode section.

The registers are buffered and appear to the computer UNIBUS as a single untt load. The DAA channel looks 11ke one channel to the UNIBUS and the interrupts appear as one hardware interrupt, but generate 25 unfque vectors starting at location 400 in the PDP-11. The error interrupt is the highest priority, the eight end-of-channel operations are the next level, and the $16 \mathrm{GL}^{\prime} \mathrm{s}$ are the lowest level. Al1 25 interrupts appear as one level to DEC and can be assigned to any one of the BR levels. The first units are assigned to the BR5 level. 
Dec. Reg.

CSR \#1
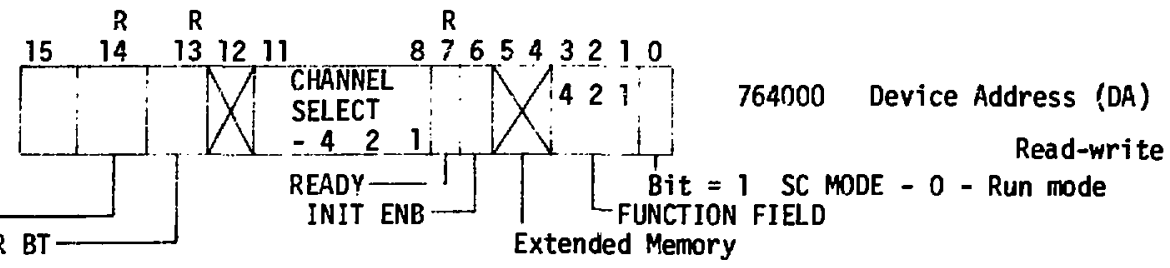

PDR

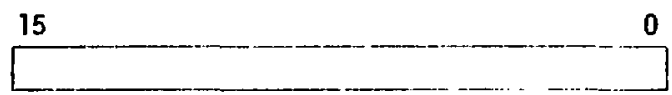

764002 (DA) Read-write

Used to load IR \& Control Memory from PDP-11

15 0

MASK

MASK's for GL $1-16$ interrupts

764004 (DA) Read-write

File Reg.

CTR

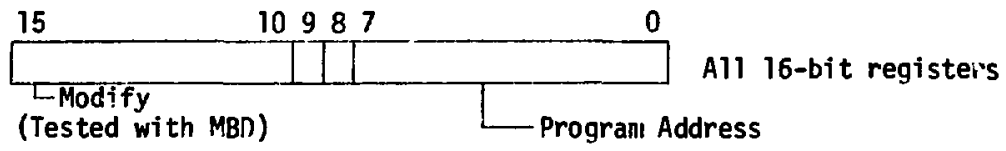

ILR Instruction list (list pointer)

WCR Word Count (Event length or \# events in 1ist)

DAR Data Address (Data List START ADDRESS)

CER CAMAC Command (CNAF 16 bits, except F8)

GPR . General Purpose (Free register)

Channel Reg.

MAR

IMDR

CAMAC Reg.

BDR \#1,\#2

GLR

BAR

CNAF
Memory Address Reg. (DMA start address)

Memory Data Reg. (DMA Data Reg.)

Read-write from MBD

Branch Data Register ("11 is 1-16) ( $\# 2$ is 17-24)

Graded L's Reg. (1-16 CAMAC INT., 17-24 channel req.)

Branch Address (command register)

\begin{tabular}{|lll|lll|l|l|l|l|l|}
15 & & -12 & 11 & 98 & 4 & 0 \\
$16^{F}$ & 4 & 2 & 1 & $4^{C}$ & 2 & 1 & $N(5)$ & $A(4)$ \\
\hline
\end{tabular}

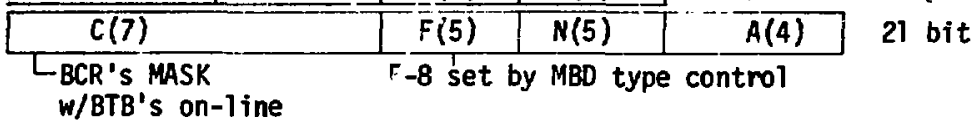

The microprogrammed processor is a full-fledged processor and is the control device that gives the MBD the speed and flexibility required. The processor's prime function is to command the branch and transfer data between the branch and the computer. Microprocessor design has developed to the point where it is faster and requires less hardware 4 to connect several registers via buses and a processor, than with gates alore.

The heart of the processor is the arithmetic and logic unft (ALU) which connects the Source bus and the Destination bus and allows transfers between aly of the registers connected to the buses in one micro instruction of the Alu. One of the 
TABLE II

MBD INSTRUCTION SET

NORMAL $\underline{\text { IR }}$

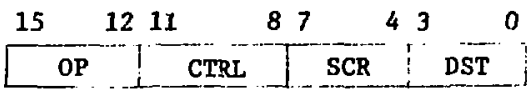

IR - Instruction Register

OP-Code Instruction

$\begin{array}{lllll}15 & 14 & 13 & 12 & \text { Name }\end{array}$

$\begin{array}{lllll}0 & 0 & 0 & 0 & \text { MOV }\end{array}$

$\begin{array}{lllll}0 & 0 & 0 & I & \text { INM }\end{array}$

$\begin{array}{lllll}0 & 0 & 1 & 0 & \text { DEM }\end{array}$

$\begin{array}{lllll}0 & 0 & 1 & 1 & \mathrm{ADD}\end{array}$

$\begin{array}{lllll}0 & 1 & 0 & 0 & \text { SUB }\end{array}$

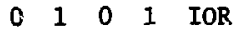

$\begin{array}{lllll}0 & 1 & 1 & 0 & \mathrm{XOR}\end{array}$

$\begin{array}{lllll}0 & 1 & 1 & 1 & \text { AND }\end{array}$

NOT NORMAL IR

oP-Code Instruclion

$\begin{array}{lllll}1 & 0 & 0 & 0 & \text { BCT }\end{array}$

$100010 \mathrm{BCF}$

$\begin{array}{lllll}1 & 0 & 1 & 0 & \mathrm{JVC}\end{array}$

$\begin{array}{lllll}1 & 0 & 1 & 1 & \text { STO }\end{array}$

$\begin{array}{lllll}1 & 1 & 0 & 0 & \text { LOD }\end{array}$

$\begin{array}{lllll}1 & 1 & 0 & 1 & \text { SHF }\end{array}$

$\begin{array}{lllll}1 & 1 & 1 & 0 & \text { LCI }\end{array}$

$\begin{array}{lllll}1 & 1 & 1 & 1 & -\end{array}$
Move $S$ to $D$, CTRL

Increment $S$, store in $D \& S$, CTRL

Decrement $S$, store in D\&S, CTRL

ADD $T$ to $S$, store in $I$, CTRL

SUBTRACT $T$ from $S$, store in D, CTRL

Inclusive OR $T, S$; store in $D$, CTRL

Exclusive $O R T, S$; store in $D$, CTRL

AND $T, S$; store in D, CTRL

\begin{tabular}{cc|ccc}
15 & 12 & 11 & 87 & 0 \\
\hline $\mathrm{OP}$ & & $\mathrm{COND}$ & $\mathrm{ADDR}$ \\
\hline
\end{tabular}

Branch to ADDR if COND TRUE

1 cycle $\mathrm{PC}=\mathrm{PC}+1$ for COND FALSE

Branch to ADDR if COND FALSE

$P C=P C+I$ for COND TRUE

1 cycie

JUMP VIA LOW BYTE IN CTR (File Reg.)

1 cycle

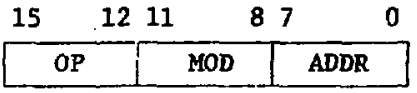

Bit $(11=1)$, S or D is PDR Reg.

Store value in $T$ REG into $\mathrm{CM}$ at ADDR

EXT. cycle

Load value at $A D D R$ into $T$ REG

EXT. cycle

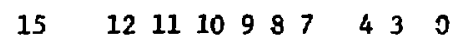

OP ${ }_{(16) \text { b1ts, B1t }(8=1) \text { Right, }}$

$50 \mathrm{~ns} / \mathrm{bit}$

SHIFT N $(1-16)$ b1ts, Blt $(8=1)$ Right, $(8=0 ;$ Left

B1t $(9=1)$ Normal, $(9=0)$ Rotate

LOAD CTR LB from LB of IR through ALU

EXT. cycle Spare

functions of the processor is to create (mulelplex) and control sight DMA channels. The information pertinent tr. the DMA oper stion is stored iil $48 \mathrm{f} 11 \mathrm{e}$ registers, all of which are connected to the $S$ and $D$ buses. The registers are organized in elght groups of $\mathrm{six}$ registers; each group contalns information for one of the eight DKA channels. The branch and computer Interface registers are connected to the $S$ and $D$ buses, whtch glves the processor control of the communication between the CAMAC branch and the computer $I / 0$. The control memory (Ci1) contains the microprograms that define the transfer sequences. The reed-write memory has 256 16-bit words and an access time of approxinately 70 nsec.

Microinutructions are executed in four clock perlods, which are Initially set at 400 nsec. The bastc clock is $10 \mathrm{MHz}$, but can be adjusted over a range of 1-25 $\mathrm{MHz}$. The Instructions are detalled In Table II and the ingtruction regiater (IR) decoding is shown in Tabje III. The thatruction set Is divided Into normal and not-normai Inatructions. Each of the normal instructions can select one of 16 control functions, a source regleter, and a destination register. The normal instructions are: $\because$ 


\section{MBD INSTRUCTION REGISTER}

IR

\begin{tabular}{llllll}
\multicolumn{4}{c}{ IR } & & \\
11 & 10 & 9 & 8 & & CTRL or \\
\hline 0 & 0 & 0 & 0 & & NONE \\
0 & 0 & 0 & 1 & DCH 2C \\
0 & 0 & 1 & 0 & DCH RD \\
0 & 0 & 1 & 1 & DCH WT \\
0 & 1 & 0 & 0 & \\
0 & 1 & 0 & 1 & BRN C \\
0 & 1 & 1 & 0 & BR CC \\
0 & 1 & 1 & 1 & \\
1 & 0 & 0 & 0 & EXIT 1 \\
1 & 0 & 0 & 1 & EXIT 2 \\
1 & 0 & 1 & 0 & EXIT 3 \\
1 & 0 & 1 & 1 & XEQ INT (X) \\
1 & 1 & 0 & 0 & PRL ST $(X)$ \\
1 & 1 & 0 & 1 & \\
1 & 1 & 1 & 0 & RST CEL \\
1 & 1 & 1 & 1 & BZ COM
\end{tabular}

15

1211

87

430

OP

CTRL SRC

DST

\begin{tabular}{|c|c|c|c|c|c|c|c|c|c|c|}
\hline \multirow[b]{2}{*}{ TEST } & \multicolumn{4}{|c|}{$\underline{\mathrm{IR}}$} & \multicolumn{5}{|c|}{$\underline{\mathrm{IR}}$} & \multirow[b]{2}{*}{$\underline{\text { DST }}$} \\
\hline & $\underline{7}$ & 6 & 5 & 4 & $\underline{\mathrm{SRC}}$ & 3 & 2 & 1 & $\underline{0}$ & \\
\hline NONE & 0 & 0 & 0 & 0 & NONE & 0 & 0 & 0 & 0 & MONE \\
\hline DCH BSY & 0 & 0 & 0 & 1 & ILR & 0 & 0 & 0 & 1 & ILR \\
\hline BR BUSY & 0 & 0 & 1 & 0 & DAR & 0 & 0 & 1 & 0 & DAR \\
\hline INT BSY & 0 & 0 & 1 & 1 & WCR & 0 & 0 & 1 & 1 & WCR \\
\hline NEG FLAG & 0 & 1 & 0 & 0 & CCR & 0 & 1 & 0 & 0 & CCR \\
\hline ZERD FLAG & 0 & 1 & 0 & 1 & & 0 & 1 & 0 & 1 & CTR \\
\hline ZERO LO BYTE & 0 & 1 & 1 & 0 & GPR & 0 & 1 & 1 & 0 & GPR \\
\hline CARRY FLAG & 0 & $i$ & 1 & 1 & PC & 0 & 1 & 1 & 1 & CTR LB \\
\hline "Q" FLAG & 1 & 0 & 0 & 0 & & 1 & 0 & 0 & 0 & DGLR $(1-16)$ \\
\hline "X" FLAG & 1 & 0 & 0 & 1 & MDR & 1 & 0 & 0 & 1 & $M D R$ \\
\hline CTR BIT \#10 & 1 & 0 & 1 & 0 & MAR & 1 & 0 & 1 & 0 & MAR \\
\hline CTR BIT \#11 & 1 & 0 & 1 & 1 & BDR \#1 & 1 & 0 & 1 & 1 & BDR \#1 $(1-16)$ \\
\hline CTR BIT \#12 & 1 & 1 & 0 & 0 & BDR \#2 & 1 & 1 & 0 & 0 & BDR \#2 (17 - 24) \\
\hline CTR BIT \#13 & 1 & 1 & 0 & 1 & & 1 & 1 & 0 & 1 & BAR \\
\hline CTR BIT \#14 & 1 & 1 & 1 & 0 & PDR & 1 & 1 & 1 & 0 & PDR \\
\hline CTR BIT \#15 & 1 & 1 & 1 & 1 & $\mathrm{CCL}$ & 1 & 1 & 1 & 1 & \\
\hline
\end{tabular}

more, increment, decrement, add, subtract, inclusive OR, exclusive $O R$, and AND. The not-normal set consists of the branch-1f-true, the branch-1f-false, jump via a low byte in CTR, store, load, shift-Tregister, and load CTR LB from IR LB. The branch instructions can select one of 16 conditions for test.

By programing convention only the file registers are assigned a particular function with the exception of the control register (CTR). The low bvte of the CTR is connected directly to the PC reglater and contains the address of the service program in control memory. Bits of the high order byte can be tested by the control program to determine which alternative procedure to execute. The Instruction location register (ILR) contalns the address of the next word in the PDP-11 core memory instruction list.

The data address register (DAR) contains the pointer to the next word in the data 1ist. The word count register (WCR) contains the number of words to be transferred to the data 11st. The CAMAC command register (CCR) contains the CAMAC function and CAMAC device address, minus the F8 b1t, which is supplied by the type of control command that loads the CCR command Into the branch address reglster (BAR). The general purpose register (GPR) Is a free regliter and may be used as the programmer desires. For an example, it may be used to create loops, as an Index register, or as a counter.

The channel request logtc is the area that ties the three mafor areas together and is the 
starting point for all run-mode operations. Understanding this area of channel requests, interrupts, exits, and priorties is the key to understanding the MBD and Its capabilities.

After initializing the processor, which will be discussed later, operation begins by making a channel request. Each of the elght channels has two sources: the PDP-11 computer and a GL in CAMAC. The computer request is higher priortty than CAMAC. The eight channels have a priority structure 0-7 with channel 7 the highest priority. With the selection of a channel the group of si: file registers associated with that channel are connected to the $S$ and $D$ buses. During the arbitration of the priority the program counter is reset to zero; if the channel selected to run has as a source the PDP-11, then the PC register is incremented. A minimum of $150 \mathrm{nsec}$ delay between incrementing the $P C$ and the first read of the control memory allows sutfictent time for the memory addressing to stabilize.

The basic operation of the processor is that a chanuel is selected and if its source was CAMAC, then the instruction in control memory location zero is executed. Location zero w11l contain a JVC Instruction, which is a jump via low byte In CTR register. This allows each channel a link to its own microprogram. If the source was the PDP-11 then execution will start at location "1" of central memory. Starting at location "1" will be a file register inftalize routine using channel transfers. This requires approximately 20 instructions for the six file registers in a group, which will be used by each channel during system initialize to load all the file registers and will be used as required by channels to reinitialize during the run phase. When a transfer is completed, then an end-of-block interrupt for that channel is sent to the PDP-11 by a control command. The PDP-11 recognizes the 1nterrupt and issues a channel request that will reinitialize that channel, if that is desired.

Once the processor is executing a program it cannot be 1rterrupted and will relinguish control to the channel request $\log 1 \mathrm{c}$ by executing cne of three exit control commands. Three types of exits are required to establish the desired control of the three registers in the channel select logic. The three registers are: the program request latch (PRL), the channel enable latch (CEL), and the channel
Initialize 1atch (CIL). The PRL register can be selectively set with a control command and can be selectively reset with an exit 2 command. The PRI is used to hold a channel request while giving up temporary control to the channel select logic with an extt 1 command. If a channel of higher priority Is not requested, then control w1ll return to the channel in the PRL. Control w111 eventually return, even if other higher prlortty channels take the processor for periods of tIme, when PRL is the highest priority. The CIL register is loaded from the CSR register channel select bits. The CIL is reget by any exit if the channel running was a computer source. The CEL reglster is a mask register for the 8-channel requests orlginating In CAMAC. Exit 2 w111 do a selective set of CEL which is the way of enabling that channel. Exit 3 will cause a selective reset of CEL and will be used at the end of the list when chaining. A control command will do a complete reset of the CEL if required.

The operation of the processor is such that any exit causes a temporary stop. If there is no request, the unit remains in the stop mode until a request is made from elther the computer or CAMAC. If there is a request from CAMAC (BD) then a BG operation is automatically started and the channel select logic waits for completion of the GL cycle before priority is arbitrated. The $C I I$ register may contain a request and also the PRL may have a request.

The timing diagrams for the system are shown in Figs 2 and 3. The basic clock for the MBD $1 a$ an adjustable $10 \mathrm{MHz}$ oscillator, which is on whenever power is applied to the unit. The basic timing is derived from a four-stage ring counter. If the clock is set at $10 \mathrm{MHz}$ then the four subcycles of the counter are $100 \mathrm{nsec}$ each. By proper gating of the counter subcycles (TS1-TS-4) with the clock and not-clock signals, then any $50 \mathrm{nsec}$ increment of time can be obtalned.

The timing for a normal instruction is shown in Fig. 2. During TS1 the instruction is loaded Into the IR register and decoded. At TS2 the source is enabled to the $S$ bus and the PC counter 18 incremented. During TS2 and the first half of TS3 the ALU operation takes place and at TS32 the output of $A L U$ is loaded into the $T$ register and gate to the $D$ bus. At TS4 the data on the D bus are enabled to the destination register. If a control comand Is programmed this occurs at TS42. 
TIMING OF KBD

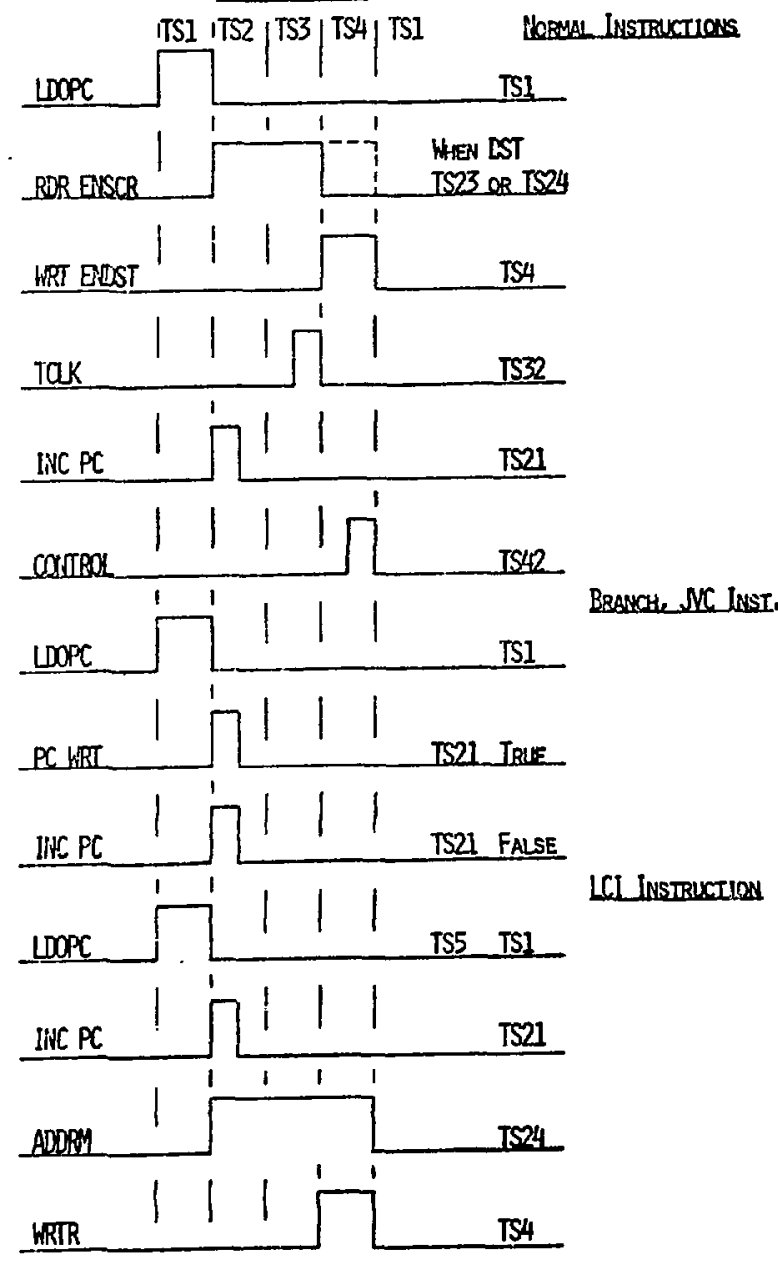

F1g. 2

The not-normal instructions require some different and spectal timing. The BCT, BCF, and JVC instructions are very simple and require only TS1 and TS2 times. At TS1 the IR register is loaded and decoded. At TS2 the PC counter is incremented or loaded with the low byte of the IR register, whichever is correct for the condition tested. The JVC instruction 1a the same except at TS2 the low byte of CTR is loaded into the PC counter.

The shift (SHF) instruction requires special timing. The shift is on the $T$ register and is an $N(1-16)$ bit right or left, normal or rotate, shift and the speed $1 \mathrm{~s} 50 \mathrm{nsec} / \mathrm{bit}$. The timing of the SHF Instruction is such that TS1-4 is normal and if additional ti:ne is required to complete the shift, the ring counter i.s held in TS4 position until the shift is completed; then it is released to perform the

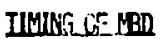

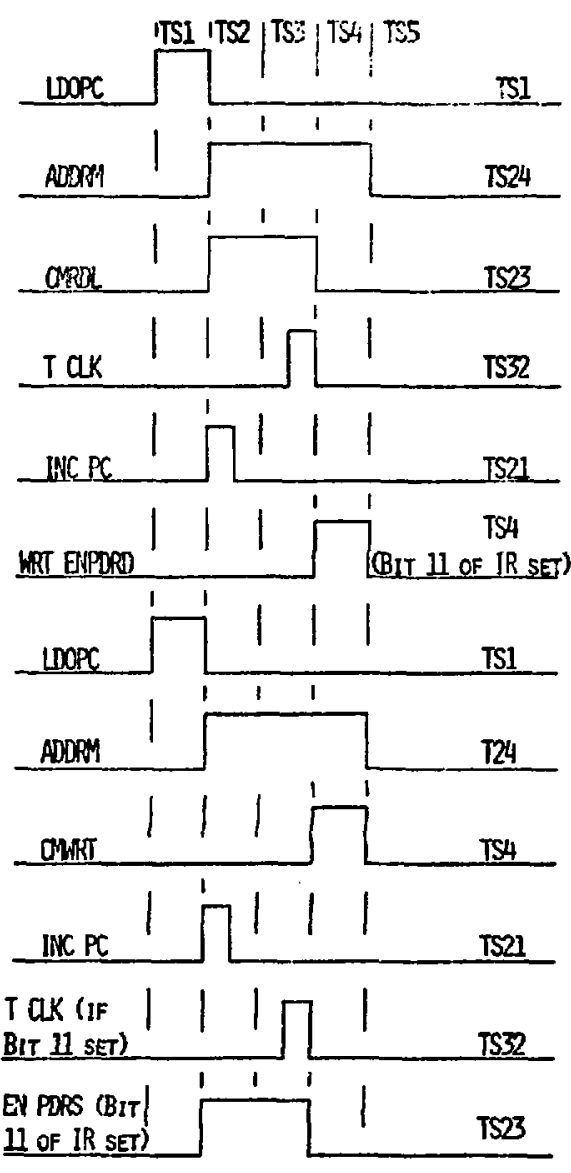

LaA INSTBICTION

STORE JWSTRUCTIOHS
Fig. 3

next instruction.

The LOD, STO, and LCI instructions require an extra subcycle (TS5). A normal load reads from central memory the word addressed in the low byte of the load instruction and stores that word in the $T$ register. If bit il is set in the load instruction then the word loaded in $T$ regiater will be also loaded in the PDR register. Store instruction is the reverse operation of load. For normal sTo the word In $T$ register is stored in memory location addressed by low byte of instruction In IR register. If bit 11 is set the word in PDR is transferred to $T$ register, then to memory as in a normal instiuction. The load and store from PDR option is the path for loading and checking the control memory programs. The LCI loads the CTR low byte from the low byte of the IR register. The path is through 
the ALU which puts it in the same timing class as load-store instructions.

\section{SINGLE-CYCLE MODE OF THE MBD}

The run mode, or normal mode, of operation has been discussed. This is the mode after initializing, when the unit is operating as a DMA channel multiplexer.

The single-cycle mode is the mode used for initializing, loading the control memory, and checkout and testing of the MBD. The control is through the CSR register as discussed in Table $I$. The controlling source can be a program transfer from the PDP11 computer or from the manual control console, which is a PDP-11 simulator. Operation of and from the control console will be discussed later.

In the single-cycle mode the MBD can be given commands through the function bits of the CSR regj.ster. Of a possible eight, five commands have been implemented as stated below:

1. Reset MBD - clears all request latches (CIL, PRL, CEL, STOP, CCL, PC), sets single-cycle mode, Ready set by strobe.

2. Execute IR - executes instruction in IR register, inhibits INCPC and LDOPC, End Instruction set Ready.

3. Load IR - load IR register with contents of PDR register, End Instruction set Ready.

4. Single Instruction - sequential central memory locations using PC counter, Fnd Instruction set Ready.

5. Channel Initlalize - bits $(8,9,10)$ of CSR set CIL register to desired channe1; bit 0 of CSR determines mode of operation, if equal to 1 set single-cycle mode, If equal to 0 set run mode. Initialize channel accepted by MBD set Ready.

0,6 , No Operation, return Ready with strobe.

7 .

Command 5 can be given with MBD in the run mode and is the path for the computer to make a channel request in the MBD. All other commands are to be used in the single-cycle mode and should be initially preceded by Reset MBD, which sets the single-cycle mode. Run mode 18 set with command 5 and $a$ in location "0."

The other controls in the CSR register are somewhat standard PDP-11 controls. Interrupt enable is the enable for the 25 interrupts of the MBD. The
Ready bit is testable by the PDP-11 program and is the Indication that MBD has completed the last command and is ready for the next coumand. The error interrupt does not identify the source of error, but testing bits 13 and 14 of the CSR register will identify branch or bus errors.

MBD MaNUAL CONTROL CONSOLE

The control console, a separate untt, was designed for two purposes: to facilitete checkout and testing, and to operate the MBD as a stand-alone branch driver.

The operation of the console is that of a PDP-11 simulator and connects to the MBD through the UNIBUS connector. The console cannot be connected to the MBD at the same time as the PDP-11. The units have 16 switches for entering data or address into their respective registers in the unit. The register can be loaded elther from the console switches or from the UNIBUS, depending on the type of transfer executed. Lights on the console display the contents of the data and address registers.

The units will be used primartly for progrm I/O transfers (DATO and DATI). The sequence for a DATO transfer 18 as follows:

1. Load data to be transferred Into the console switches and place in data regtster by pressing load data switch.

2. Load address of device In address reglster by pressing load address switch.

3. Place the read/write switch to write position, then start the DATO operation by pressing the program transfer switch.

The DATI operation is as follows:

1. Load the address of device in address register.

2. Set read/write to read and start transfer switch. The data transferred from the device will appear In the reglster and data 11ghts.

The console has an INIT switch which 18 the master clear for the system.

The operation of both types of priortty transfer can be tested. For a bus request (BR) a light on the console indicates the request and pressing the bus grant (BG) switch allows the transfer to complete. The interrupt vector will appear in the data lamps.

The nonprocessor request (NPR) is bastcally the same as the BR. The NPR lamp Indicates the requeat and pressing the nonprocess grant (NPG) switch 
completes the cycle. One difference 18, if the transfer of data is from the console, then it must be luaded into the data register before the grant is initlated. If the transfer is to the console, the data will appear in the data lamps. Generally, transfers and interrupts will be initiated in the CAMAC hardware. A channel request can be initiated with a program transfer to the CSR register in the MBD from the control console.

\section{MBD SOFTWARE}

As of this writing, software does not exist for the MBD. What w11 be discussed are the inttializing procedures for the MBD and CAMAC system and the type of sof tware that is planned for development.

The first step in initializing the MBD is to load the control memory with the programs required to control the channels and the CAYAC system during the run mode of operation. The control memory is loaded and checked using the single-cycle mode of the MBD.

The following sequence is required:

1. Issue Function 1 - Reset MBD, which clears latches and puts in single-cycle mode.

2. Load PDR register with MBD instruction STO from PDR register.

3. Issue Function 3 - load IR from PDR register.

4. Load PDR register with instruction or data to be stored in MBD control memory.

5. Issue Function 2 - execute IR, which stores the word in PDR register in control memory 10cation specified by low byte of IR register. To verify the loading, the following sequence

is required:

1. Load PDR register with MBD 1nstruction. LOD from PDR register.

2. Issue Function 3 - load IR from PDR register.

3. Issue Function 2 - execute IR, which reads the control memory cell addressed by low byte of IR register and cransfers that word to the PDR register.

4. Read PDR register and compare with word written into MBD central memory during load sequence.

Af ter loading and verffying the loading of control memory, the system is put in the run mode and the file registers are loaded from a list in the PDP-11 memory. The program for Inftializing the file registers from a 11st in the PDP-11 is shown below. To inftialize a channel the request Is made via the CSR register and the ready bit is set when it is initialized.

\section{Channel Initiallze Program}

\begin{tabular}{cl} 
CM Location & Instruction \\
\cline { 1 - 3 } & JVC \\
1 & MOV PDR, ILR, O \\
2 & INM ILR, MAR, DCH RDR \\
3 & BCT DCH BSY, 3 \\
4 & MOV MDR, CTR \\
5 & INM ILR, MAR, DCH RDR \\
6 & BCT DCH BSY, 6 \\
7 & MOV MDR, DAR \\
: & : (3 Instructions per file register) \\
Last & MOV MDR, GPR, Exit 2
\end{tabular}

The above procedure is reentrant fron all channels. The same procedure is used for relnitializing a channel during the run mode of operation. When a channel requires inttlalizing, an end-of-block interrupt is set for that channel with a control command. When the interrupt is recognized, then the channel is initialized by a channel request from the PDP-11 as described above.

The sane procedure for loading file registers from a channel can be used for loading sectlons of control memory during the cun mode. That 18 , a program could be swapped in and out during run mode using a channel program.

Once the MBD has been Inftialized, then the CAMAC system must be Inftlalized. This can be done using a low priority channel and using the list mode of operation. To get a channel to run from the computer can be accomplished by setting a testable bit in the CTR regiater during the inftializing phase and teating that bit to determine the type of exit required for that channel. The general Initialize routine for CAMAC depends on the system configuration. The type of comands required are: enable branch demand (BD) in each Type $A$, reoet the Inhibits, enable the L's in nodules, and set up MASK registers.

Several levels of diagnostics are planned. The first level will be using the manual control console. These will vary from a few key-in instructions to a full-blown syscem loaded from CAMA, and data-recording through CAKAC.

Diagnostics on the computer will verify various levels of system operation. The first level is that 
the computer functions properly; second, that MBD can be Initialized; third, that MBD itself is functloning properly; fourth, that the branch Is operating down to a Type A controller; and fifth, that the system from CAMAC modules to the computer are functioning properly.

One of the goals of standardization in the LAMPF data-acquisition system is software standards made possible through hardware standards. These standards w11 range from the disc operating system of the PDP-11 to the operation of the Internal data links, and down to the driver (subprograms) routines used in the MBD. R. F. Thomas discusses in h1s LAMPF memo, "Possib1?1t1es for a standard CAMAC Processor Language," 7 a proposal for a CAMAC language and how the MBD would be programed to serye as its virtual controller.

\section{PROPOSED USES OF MBD AND DESIGN OPTIONS}

The MBD was designed primarily'to meet the requirements of the LAMPF data-acquisition syotem. The LAMPF terminal computer w11 initially use a standard MBD, but one of the design options is to expand the MBD to 16 or 24 DMA channels, which w111 be required of the terminal computer when LAMP is at full capac1ty.

One possible major requirenent is the need of a manual, flextble branch driver. Witr a manual console and a conventent means of loading programs, the MBD becomea a very flextble, powerful manual controller. The loading can be accomplished with peripheral interfaces in CAMAC and a bootetrap loader in the MBD. With a recording capability, or a link to recording capability (terminal computer), the MBD could control a omall, aimple experiment. One design option, the expansion of mewory in the MBD, makes this very feastble. W1th the present memory design the MBD can be expanded to 512 worda of menory and with the new 256-bit newory chips. the unit has space for over 1000 words of wenory, if that were ever required.

Another possible use of the MBD is as a resote branch driver. The computer bus is 11 ted to 50 ft or less, and the present branch dea, is are also Iimited to $50 \mathrm{ft}$ or lese. Bach of these interfaces has tining linttation, large nubers of wires, and wajor redeaign effort to go any diatance. With two MBD' $^{\prime}$ and usting the high-oped data-1ink nodules (developed at LAMPF for conputer-to-computer transfers through (AMAC), then a branch way be operated at a remote distance of a few thousand feet without any penalty of operations performance and major redesigns of the gystem.

$A$ very minor modification will convert the $M B D$ from binary arithmetic to 2 's complenent arithetic if this is required. One design option that is open, but w111 probably never be used, 1s the add1tion of a second branch to the MBD. The nost probable solution would be to add a second MBD and wodify the Interrupt assigments of the second unte.

\section{MBD HARDWARE AND FABRICATIOA}

Figure 4 is a photograph of the MBD and control console. The systen was designed and fabricated using the computer autowated aysten hardware (CASH) developed by Standard Logic, Inc. The CASH hardware 18 designed for use with computer-aided deeign (CAD) technology and is supported by a conplete line of systens software, computertzed documentation, and semiautomatic wring.

The MBD was destgned in the TD-36 drawer, which has $3 \frac{1}{2}$ in. panel height, alides, and two cooling fans. The drawer has two separate 18-card planes. The planes are wred separately and Interconnected through cables and two connector carda. The top plane has 14 CasH cards and houses the aicroprocessor. The botton plane his 13 CASH carde and houses the computer interface and the branch driver. All cabling to to the bottom plane. The two CAMA port connectors are on the front panel and the computer UNIBUS concector 1 s on the rear panel. The control console pluge into the conputer connector.

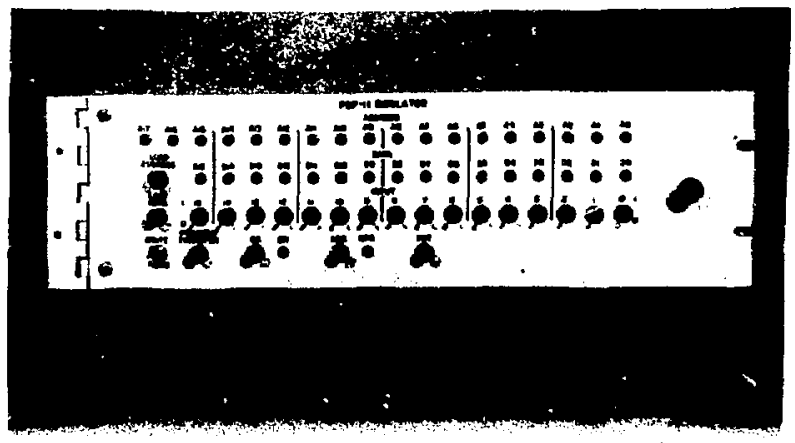

FIs. 4 
The eight DMA channel, 256 words of memory model of the MBD has 500 integrated circuits and requires a separate $5 \mathrm{Vdc}, 25$ A power supply.

The CASH system has a variety of cards using 14-, 16-, and 24-pin sockets for integrated circuits, and the wiring is a two-level wirewrap using No. 30 wire. The unit has 4600 wires and was wired in 40 hours using the machine-aided wiring system.

The manual console uses the CASH hardware and is housed in a DC-01 vertical panel. The unit has three CASH cards and a $5 \mathrm{Vdc}, 5 \mathrm{~A}$ power supply. One cable connects the unit to the MBD. The front panel has the control switches and the address and data lights.

\section{ACKNOWLEDGMENTS}

The authors are indebted to Richard F. Thomas, Jr., Los Alamos Scientific Laboratory, by whom the MBD systems design and operation was greatly influenced, and to James A. Buchanan and Hugh V. Jones, Rice University, for the intial development of the MBD.

\section{REFERENCES}

1. "LAMPF Data-Acquisition System," LA-4504-MS, Los Alamos Scientific Laboratory, Los Alamos, N. M. 87544, Aug. 1970.

2. J. A. Buchanan and H. V. Jones, "CAMAC MultiMicroprogrammed Io Processor," IEEE Trans. on Nuc1. Sc1., Vol. NS-19, No. 1, Feb. 1972, p. 682 .

3. "A Modular Instrumentation System for Data Handling," EURATOM 4100e. Available from L. Costrell, Ne.t1. Bureau of Standards, Washington, D. C. 20234.

4. "Organization of Multicrate Systems," EURATOM $4600 e$, ibid.

5. PDP-11 UNIBUS Interface Manual, DEC-11-H1AA-D.

6. PDP-11 Handbook 112X01269, AJOF1150.

7. "Possibilities for a Standard CAMAC Processor Language," Notes by R. F. Thomas, Jr ., MP-1, LASL, Los Alamos, N. M. 87544, Oct. 20, 1971. 